\title{
Effects of Broccoli Rotation on Lettuce Drop Caused by Sclerotinia minor and on the Population Density of Sclerotia in Soil
}

\author{
Jianjun Hao and Krishna V. Subbarao, Department of Plant Pathology, University of California, Davis, c/o \\ United States Agricultural Research Station, Salinas, CA 93905; and Steven T. Koike, University of California Co- \\ operative Extension, Salinas 93901
}

\begin{abstract}
Hao, J. J., Subbarao, K. V., and Koike, S. T. 2003. Effects of broccoli rotation on lettuce drop caused by Sclerotinia minor and on the population density of sclerotia in soil. Plant Dis. 87:159166.

Field experiments were conducted at Spence Road site and at the Hartnell College East Campus site in Salinas, CA, to determine the effects of crop rotation with broccoli or a fallow period on lettuce drop caused by Sclerotinia minor and the density of pathogen sclerotia in the soil. Treatments at the Spence Road site with low inoculum density ( $<7$ sclerotia per $100 \mathrm{~cm}^{3}$ of soil) distributed randomly included: successive crops of lettuce (LLL), lettuce rotated with broccoli (LBL), and lettuce followed by a fallow period (LFL). Treatments at the Hartnell site with high inoculum density ( $>7$ sclerotia per $100 \mathrm{~cm}^{3}$ of soil) distributed uniformly included: continuous lettuce (LLLL), broccoli-lettuce-broccoli-lettuce (BLBL), broccoli-broccoli-lettuce-lettuce (BBLL), and fallow-lettuce-fallow-lettuce (FLFL). At the Spence Road site, continuous lettuce did not increase lettuce drop incidence for at least 2 years, although an increase in soilborne sclerotia was observed annually but was below the threshold at which a correlation between inoculum density and disease incidence is observed. Rotation with broccoli resulted in small reductions in disease incidence only in the first year. The density of sclerotia was lowest in the LFL treatment, and the highest in the LLL. At the Hartnell site, rotation with broccoli significantly reduced both sclerotia and lettuce drop incidence. The number of broccoli crops rather than the sequence of lettuce rotations with broccoli was critical for reducing the numbers of $S$. minor sclerotia in soil. Fallowing after a lettuce crop resulted in marginal reductions in sclerotia and lettuce drop incidence. Viability of recovered sclerotia was not significantly different between treatments, although differences between seasons were detected. Results suggest that rotations with broccoli can be a practical lettuce drop management strategy.
\end{abstract}

Lettuce drop, caused by two Sclerotinia spp., S. minor Jagger and S. sclerotiorum (Lib.) de Bary, is an important disease of lettuce (Lactuca sativa L.) (22,23). In California, S. minor is the predominant species causing lettuce drop in the coastal Salinas and Santa Maria Valleys, where more than $65 \%$ of lettuce in the United States is produced. In the noncoastal San Joaquin Valley of California, S. sclerotiorum is the predominant species causing lettuce drop $(8,23)$. Both species have extensive host ranges and survive as sclerotia in soil for up to 10 years $(11,20,23)$. Sclerotia are the primary source of inoculum for $S$. minor. Because of its wide host range, prolonged survival, and aggressiveness, $S$. minor causes severe losses in lettuce in California each year. Thus, our current investigations have emphasized this species.

A number of tactics have been developed for lettuce drop management

Corresponding author: K. V. Subbarao
E-mail: kvsubbarao@ucdavis.edu

Accepted for publication 13 September 2002.

Publication no. D-2002-1120-01R

(C) 2003 The American Phytopathological Society
$(10,15,22,27,28)$. However, none of the management approaches alone give adequate control of lettuce drop. Currently, control on lettuce, and the activity of those registered is limited (23). For example, 2,6-dichloro-4-nitroaniline (15), iprodione, and vinclozolin (29) have short periods of effectiveness in the soil when applied immediately after thinning. Efficacy of preplant applications of metham-sodium is greatly affected by soil conditions and it is toxic to lettuce (23). Commercial cultivars of lettuce all are susceptible to $S$. minor and identification of resistant germ plasm has had limited success $(1,23)$. Biological control of $S$. minor has shown potential $(2,3)$, but the efficacy of the biocontrol agents in the field on a commercial scale remains questionable.

Attempts at managing $S$. minor through cultural practices have been efficacious but ual fields. Deep plowing was employed in the late 1970s to reduce populations of $S$. minor sclerotia in the upper profiles of the soil (12). However, recent work (28) has demonstrated that, although deep plowing reduced the populations of $S$. minor sclerotia in soil, the increased post-deep plowing tillage operations to prepare land redisfew fungicides are registered for $S$. minor depend on the cropping history of individ- tributed inoculum from an aggregated pattern to less aggregated patterns. These tillage operations, therefore, transferred sclerotia to areas within the field that were devoid of them. Thus, lettuce drop incidence increased significantly after deep plowing (28). Subsurface drip irrigation reduces both the number of soilborne sclerotia and lettuce drop incidence (27), but the initial investment costs are high, and subsurface drip irrigation requires intensive management (23). Thus, few growers currently use these two disease management techniques.

In recent years, crop rotation has been applied successfully as a disease management tactic in different pathosystems $(4,5,13,17,30)$. Hence, it has drawn increased attention as an important disease management tool in sustainable agriculture. Although crop rotation has been reported to reduce diseases caused by $S$. sclerotiorum on other crops (5), the effects of crop rotation on lettuce drop caused by $S$. minor have not been evaluated.

One difficulty in using crop rotation to control S. minor in lettuce is the limited availability of candidate crops for rotation given the wide host range of the pathogen. Broccoli (Brassica oleracea L. var. italica L.) recently has been shown to reduce the number of Verticillium dahliae Kleb. microsclerotia in soil and the incidence of Verticillium wilt on subsequent cauliflower (B. oleracea L. var. botrytis L.) crops $(18,25,26,30)$. Broccoli and other crucifers are recognized as good candidates for disease suppression in crop rotations because of their innate glucosinolate content $(13,14,16)$. It is generally assumed that the breakdown products from glucosinolates are toxic to soilborne plant pathogens (7). S. minor also produces sclerotia $(22,23)$; therefore, we hypothesized that crop rotation with broccoli may also be effective against $S$. minor on lettuce.

Preliminary laboratory studies showed that broccoli residue significantly reduced the viability of $S$. minor sclerotia in soil (K. V. Subbarao, unpublished data). The objectives of this study were to determine the efficacy of broccoli as a rotation crop to reduce the number and viability of $S$. minor sclerotia and the incidence of lettuce drop in the field, and to determine the temporal dynamics of $S$. minor sclerotia in soil and lettuce drop development under the crop rotation system. 


\section{MATERIALS AND METHODS}

Field plot preparation and treatments. The efficacy of rotations with broccoli was tested in a field at the Spence Road site containing low density of inoculum ( $<7$ sclerotia per $100 \mathrm{~cm}^{3}$ of soil) distributed randomly (established by employing tillage operations and assaying soil for sclerotia) and in another field at the Hartnell College East Campus containing a high density of inoculum ( $>7$ sclerotia per $100 \mathrm{~cm}^{3}$ soil) distributed uniformly (established by inoculating each lettuce plant after thinning). The rationale behind these two sites was to examine if broccoli reduces the potential increase in $S$. minor sclerotia at the low inoculum density site and if it reduces the inoculum density of $S$. minor sclerotia at the high inoculum density site. In addition, we examined the effects of incorporation and removal of plant residue on subsequent inoculum levels and disease incidence at the low inoculum density site. The experiments were conducted from 1995 to 1998 so that each treatment was repeated at least once. The lettuce cv. Salinas (Pybas Vegetable Seed Co., Inc. Santa Maria, CA) and broccoli cv. Greenbelt (Rogers Seed Company, Gilroy, CA) were used in all experiments. Lettuce was planted in two rows $30 \mathrm{~cm}$ apart per bed with $100 \mathrm{~cm}$ between bed centers. Immediately after seeding, the herbicide Pronamide (Rohm and Haas Company, Philadelphia, PA) was applied to the lettuce plots at the recommended rate and watered in. After emergence, the lettuce was thinned to $30 \mathrm{~cm}$ between plants. Fiveweek-old transplants of broccoli were planted at a spacing of $15 \mathrm{~cm}$ and the herbicide DCPA (AMVAC Chemical Corporation, Los Angeles, CA) was applied at the recommended rate. Throughout the experiment, sprinkler irrigation was used at both sites to encourage lettuce drop development (27).

The Spence Road site experiment was planted in a loamy sand soil $(74.7 \%$ sand, $19.0 \%$ silt, $6.3 \%$ clay, and $1.1 \%$ organic matter, $\mathrm{pH}$ 5.6). In each of the past 10 years, the field was planted with oat (Avena sativa L.) and had no history of $S$. minor (confirmed after assaying the soil). Lime was applied to all plots before the first lettuce crop was planted to elevate soil $\mathrm{pH}$ to approximately 7.0. After thinning, all plants were inoculated with $S$. minor by a previously described method (27) and, at crop maturity, residue was incorporated. Normal tillage operations followed to establish inoculum in the soil with random inoculum distribution (8). Subsequently, three rotation treatments were established (Table 1): consecutive lettuce crops (LLL), lettuce rotated with broccoli (LBL), and lettuce rotated with a fallow period (LFL). Treatments were arranged in a randomized complete block design with four replications. Each main treatment plot was eight beds wide ( $1 \mathrm{~m}$ between bed centers) and $12 \mathrm{~m}$ long. Two-bed borders separated plots across rows and $6 \mathrm{~m}$ of bare soil separated plots along the rows to prevent plot cross-contamination.

In the treatments LLL and LBL, residues of lettuce or broccoli were incorporated in one-half of each main plot. These treatments were designated LLL-R or LBL-R. In the other half of each plot, residues were removed physically at harvest (designated LLL-N or LBL-N) to study the effects of residue management on the population density of sclerotia. Where residues were incorporated, crops were harvested at maturity and the remaining residues were chopped 2 days later using a Marvin bed mulcher mounted on a tractor, then incorporated into the soil to a depth of $20 \mathrm{~cm}$. One month after residue incorporation, the plots were reworked and beds were shaped for planting of the next rotation crop. The fallow plots were maintained and irrigated along with other treatments, except that weed removal was not done during the fallow period. The first lettuce crop at the Spence location (low inoculum density) was planted in June 1995, and spring and fall crops were planted in 1996 and 1997 for a total of five cropping seasons.

The Hartnell College East Campus experiment was planted in a loam soil $(52.3 \%$ sand, $36.3 \%$ silt, $11.5 \%$ clay, and $1.1 \%$ organic matter, $\mathrm{pH}$ 7.7). The experiment began with lettuce and broccoli in the spring of 1996, and subsequent crops were planted during the fall 1996, spring and fall 1997, and spring 1998. Plots were six beds wide and $20 \mathrm{~m}$ long, and arranged in a randomized complete block design with three replications. Plots were separated by two-bed borders and $10 \mathrm{~m}$ of bare soil between blocks to avoid plot interactions. This location had previously been used for 3 years for other experiments involving $S$. minor; therefore, sclerotia initially were present in the soil in high numbers (24) (at least 25 sclerotia per $100 \mathrm{~cm}^{3}$ of soil). However, to establish a uniform distribution of the inoculum, all plants were inoculated during spring 1996, after thinning or transplanting, as described previously (24). In the fallow treatment, autoclaved and infested rye seed (24) were pressed into the soil at intervals similar to those used for lettuce and broccoli inoculation. Therefore, all plots were treated with same amount of inoculum at the beginning. Treatments at this site included the following crop sequences: lettuce-lettuce-lettuce-lettuce (LLLL), broccoli-lettuce-broccoli-lettuce (BLBL), broccoli-broccoli-lettuce-lettuce (BBLL), and fallow-lettuce-fallow-lettuce (FLFL) (Table 1). At the end of each season, residue remaining after harvest in the corresponding lettuce or broccoli plots was incorporated into the soil as described above. At both the Spence and Hartnell sites, a crop of lettuce was planted in all plots after the final rotation treatment to determine if the effects of rotation continued in subsequent lettuce crops.

Disease incidence. At both locations, lettuce drop incidence was evaluated weekly beginning at thinning and continued until harvest. About 320 plants from the four middle beds of each plot at the Hartnell site and about 480 plants from the six middle beds of each subplot at the Spence site were evaluated for disease incidence. Lettuce plants with symptoms of clear, watery decay or wilting leaves typical of lettuce drop were recorded as diseased. The location of each plant, either diseased or healthy, was mapped to avoid recording a diseased plant more than once. Disease incidence was calculated as the

Table 1. Field cropping schedules at two locations in Salinas, CA, in which the effects of crop rotation on Sclerotinia minor sclerotial density and lettuce drop incidence were studied ${ }^{\mathrm{a}}$

\begin{tabular}{|c|c|c|c|c|c|c|c|c|c|}
\hline \multirow[b]{2}{*}{ Year } & \multicolumn{4}{|c|}{ Spence } & \multicolumn{5}{|c|}{ Hartnell } \\
\hline & Season & LLL & LBL & LFL & Season & LLLL & BLBL & BBLL & FLFL \\
\hline Pre-experiment & $\ldots$ & $\mathrm{Oat}^{\mathrm{b}}$ & $\mathrm{Oat}^{\mathrm{b}}$ & $\mathrm{Oat}^{\mathrm{b}}$ & $\ldots$ & Lettuce $^{c}$ & Lettuce $^{c}$ & Lettuce $^{c}$ & Lettuce $^{c}$ \\
\hline 1995, June & $1 \mathrm{st}$ & Lettuce* & Lettuce* & Lettuce* & $\ldots$ & Lettuce $^{c}$ & Lettuce $^{\mathrm{c}}$ & Lettuce $^{c}$ & Lettuce $^{c}$ \\
\hline 1996, spring & $2 \mathrm{nd}$ & Lettuce & Broccoli & Fallow & 1 st & Lettuce* & Broccoli* & Broccoli* & Fallow* \\
\hline 1996 , fall & $3 \mathrm{rd}$ & Lettuce & Lettuce & Lettuce & 2nd & Lettuce & Lettuce & Broccoli & Lettuce \\
\hline 1997, spring & 4th & Lettuce & Broccoli & Fallow & $3 r d$ & Lettuce & Broccoli & Lettuce & Fallow \\
\hline 1997, fall & 5 th & Lettuce & Lettuce & Lettuce & 4th & Lettuce & Lettuce & Lettuce & Lettuce \\
\hline 1998 , spring & $\ldots$ & $\ldots$ & $\ldots$ & $\ldots$ & 5th & Lettuce & Lettuce & Lettuce & Lettuce \\
\hline
\end{tabular}

a An asterisk indicates that plants were inoculated with $S$. minor at thinning or transplanting, or soil was infested with $S$. minor in the fallow treatment at the same frequency as other treatments.

b Oat crops were continuously grown for at least 5 years.

${ }^{\mathrm{c}}$ Continuous lettuce crops grown for at least 3 years at two crops/year, with a history of severe drop incidence. 
percentage of diseased plants among the total number of plants observed. At the same time, broccoli plants were monitored for symptoms of infection by $S$. minor.

Soil sampling and assay. To determine the change in the density of sclerotia over time, soil samples were collected at the beginning of each season immediately after lettuce thinning. Three arbitrary subsamples were collected from each of the four middle beds of each plot using a custom-designed soil sampling core $(4.3 \mathrm{~cm}$ diameter by $7 \mathrm{~cm}$ deep). Each sample was air dried in a paper bag at ambient temperature $\left(21 \pm 2^{\circ} \mathrm{C}\right)$ and stored for at least 30 days prior to processing. At the Hartnell site, soil samples were collected at the beginning of each season, and an additional sample was collected at the end of the season from each plot in fall 1996 and spring 1997. At the Spence site, all samples were collected at the beginning of the season.

All soil samples were assayed for $S$. $m i$ nor sclerotia using a wet-sieving technique (24). Recovered sclerotia were surface sterilized for $3 \mathrm{~min}$ in $10 \%$ bleach containing $0.53 \% \mathrm{NaOCl}$ and rinsed with sterile distilled water. The sclerotia were plated on water agar and the number of germinated sclerotia were counted after 5 days incubation at room temperature. S. minor cultures were confirmed by the emergence of typical mycelium (24).

Analysis of variance of rotation effects on disease incidence, population density of sclerotia, and sclerotial viability was performed using the SAS Mixed model procedure (ver. 7.0; SAS Institute, Inc., Cary, NC). Seasons and treatments were considered as fixed effects and block as a random effect. Least square means were used for treatment comparisons.

\section{RESULTS}

Lettuce drop incidence. At the Spence site, disease incidence averaged $46.9 \%$ in fall 1995 when each plant was inoculated at thinning (data not shown). In the subsequent seasons, disease incidence varied between 8.7 and $14 \%$ in fall 1996 and between 7.8 and $10.7 \%$ in fall 1997, depending on the treatment (Fig. 1). Disease incidence was significantly different between treatments at the Spence site, but not in 1997. The incidence of lettuce drop at Hartnell was $88.6 \%$ in spring 1996 when all of the plants were inoculated at thinning (data not shown). In the final two seasons, when all of the plots were planted with lettuce, disease incidence ranged between 29 and $73 \%$, depending on the treatment (Fig. 1). At both locations, first drop symptoms were observed after thinning. At no time were broccoli plants found to exhibit symptoms associated with $S$. minor, nor was $S$. minor isolated from broccoli plants.

At the Spence site, analyses of the combined data for 2 years showed no significant treatment effects. However, seasonal differences were detected with the incidence in fall 1997 being lower than in fall 1996 (Table 2). When the data from each year were considered separately in the analyses, treatments were significantly different in fall 1996, but not in fall 1997 (Fig. 1). Lettuce drop incidence observed in LLL-R (residue removed) was not sig-
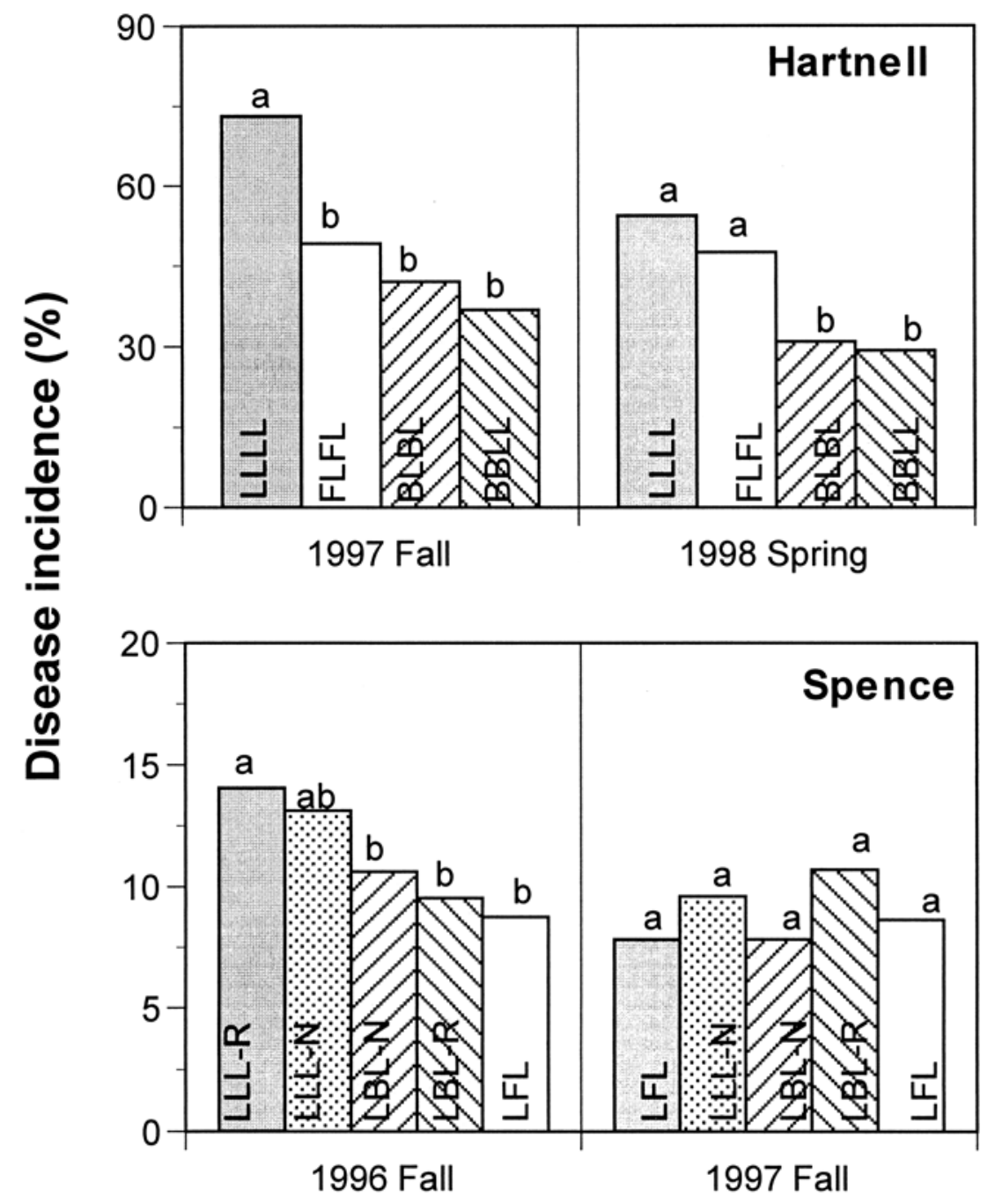

Season

Fig. 1. Effects of lettuce rotation with broccoli or a fallow period on the final incidence of lettuce drop in the last two seasons when all rotation treatments were planted with lettuce at the Hartnell and Spence field sites. Different letters above the bars indicate significant differences between treatments within a season according to a Duncan's multiple range test $(P<0.05)$. Treatment notations (crop sequences): LLLL = lettuce-lettuce-lettuce-lettuce, FLFL $=$ fallow-lettuce-fallow-lettuce, BLBL $=$ broccoli-lettuce-broccoli-lettuce. LLL-R = lettuce-lettuce-lettuce with residues incorporated in the soil, LLL-N = lettuce-lettuce-lettuce with residues removed, and LFL = lettuce-fallow-lettuce.

Table 2. Analysis of variance for effects of crop rotation (lettuce rotated with broccoli or fallow) on final incidence of lettuce drop at two field sites in Salinas, CA

\begin{tabular}{lcccc}
\hline Field site, source & $\boldsymbol{d} \boldsymbol{f}_{\mathbf{n}}^{\mathbf{a}}$ & $\boldsymbol{d f _ { \mathbf { d } } \mathbf { b }}$ & $\boldsymbol{F}^{\mathbf{c}}$ & $\boldsymbol{P r}>\boldsymbol{F}^{\mathbf{d}}$ \\
\hline Hartnell & & & & \\
Season & 1 & 8 & 4.85 & 0.0588 \\
Treatment & 3 & 8 & 5.72 & 0.0217 \\
Season-treatment & 3 & 8 & 1.23 & 0.3594 \\
Spence & & & & \\
Season & 1 & 24 & 10.27 & 0.0038 \\
Treatment & 4 & 13 & 1.17 & 0.3711 \\
Season-treatment & 4 & 24 & 3.32 & 0.0270 \\
\hline
\end{tabular}

a Numerator degrees of freedom.

${ }^{\mathrm{b}}$ Denominator degrees of freedom.

c Variance ratio.

${ }^{\mathrm{d}}$ Probabilities associated with individual $F$ tests. 
nificantly different from that in LLL-N (no residue removed); similarly, drop incidence in LBL-R was not significantly different from that observed in LBL-N (Fig. 1). In the 1996 fall crop, disease incidence in LLL-R was significantly higher than in LBL-N and LBL-R, and treatments LBL-N and LBL-R were not different from the

Table 3. Analysis of variance for crop rotation effects on populations of Sclerotinia minor sclerotia in soil at two field sites in 1996 to $1998^{\mathrm{a}}$

\begin{tabular}{lcccc}
\hline Field site, source & $\boldsymbol{d}_{\mathbf{n}}^{\mathbf{b}}$ & $\boldsymbol{d}_{\mathbf{d}}^{\mathbf{c}}$ & $\boldsymbol{F}^{\mathbf{d}}$ & $\boldsymbol{P r}>\boldsymbol{F}^{\mathbf{e}}$ \\
\hline Hartnell & 3 & & & \\
Season & 3 & 24 & 11.57 & 0.0001 \\
Treatment & 9 & 24 & 32.12 & 0.0004 \\
Season-treatment & & 58 & 2.78 & 0.0219 \\
Spence & 3 & 11 & 10.27 & 0.0001 \\
Season & 4 & 58 & 1.17 & 0.0218 \\
Treatment & 12 & 3.32 & 0.0044 \\
Season-treatment & & & \\
\hline
\end{tabular}

a Soil samples were taken at the time lettuce was thinned in each crop cycle.

b Numerator degrees of freedom.

c Denominator degrees of freedom.

d Variance ratio.

e Probabilities associated with individual $F$ tests.

fallow treatments (LFL) (Fig. 1). However, LBL-N was not significantly different from any other treatment.

At the Hartnell site, the disease incidence was significantly different $(P<0.05)$ between rotation treatments, but not between seasons (fall 1997 and spring 1998; Table 2). In fall 1997, treatments BLBL, BBLL, and FLFL had lower lettuce drop incidence than in LLLL (Fig. 1), although differences among the first three treatments were not significant relative to the LLLL treatment. Disease incidence was reduced $50.2 \%$ by treatment BBLL, $48.9 \%$ by BLBL, and $45.2 \%$ by FLFL. In spring 1998, only BLBL and BBLL resulted in further reductions in disease incidence, and no difference between LLLL and FLFL was detected (Fig. 1). Relative to the LLLL treatment, disease incidence was reduced by 46.2 and $43.1 \%$ by BBLL and BLBL, respectively, during spring 1998.
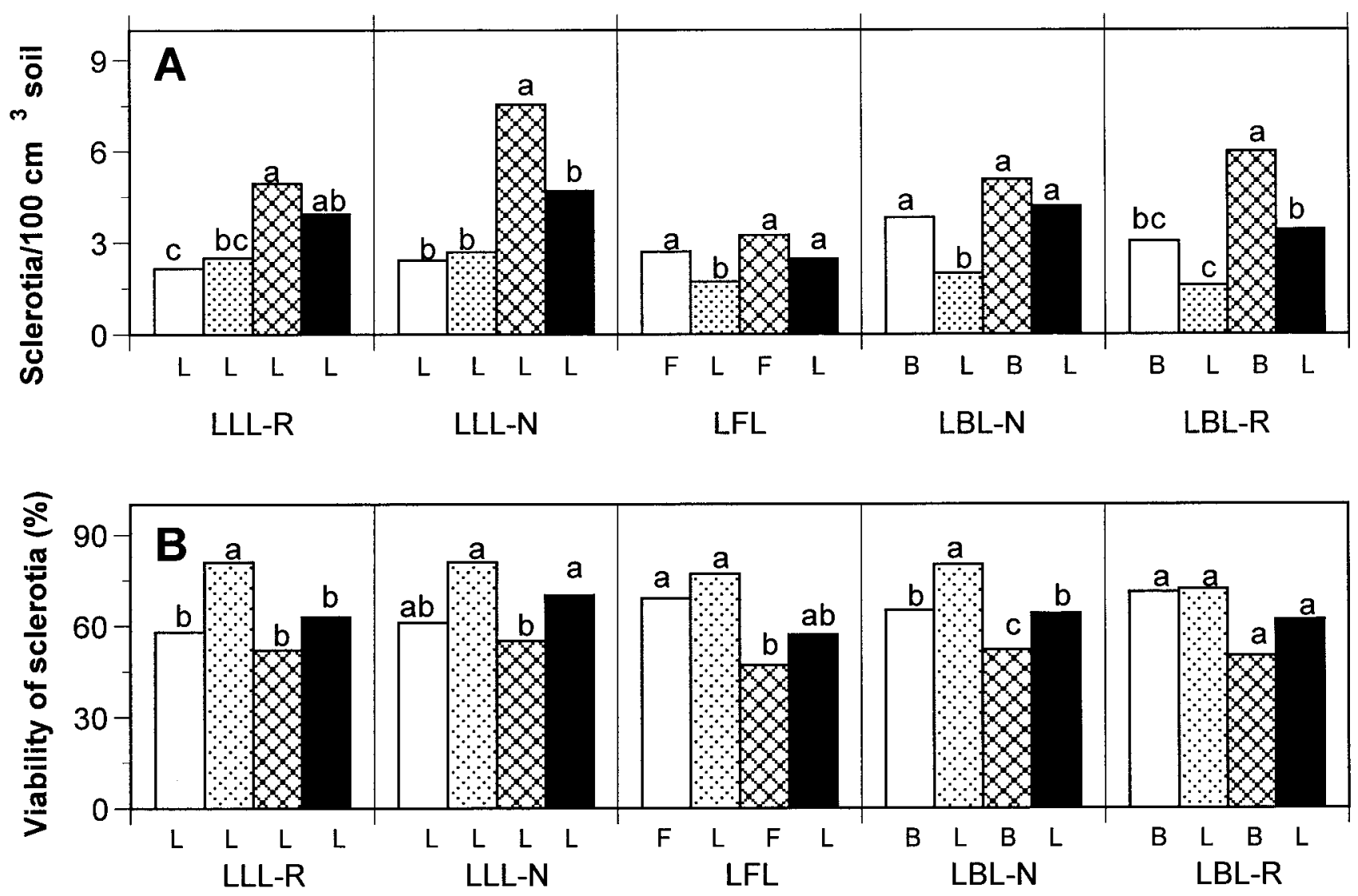

Treatment

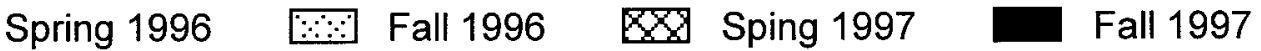

Fig. 2. Effect of lettuce rotation with broccoli or fallow on the numbers of sclerotia in $100 \mathrm{~cm}^{3}$ of soil, and viability of Sclerotinia minor sclerotia in soil at the time of thinning lettuce at the Spence site. A, Numbers of sclerotia in $100 \mathrm{~cm}^{3}$ of soil and $\mathbf{B}$, sclerotial viability in the different rotation treatments in 1996-97. Viability was calculated as the ratio of germinated sclerotia to the number recovered from soil. Letters $(\mathrm{L}=\mathrm{lettuce}, \mathrm{B}=\mathrm{broccoli}$, and $\mathrm{F}=$ fallow) below the bars indicate crops planted or left fallow during that season. The first crop in all treatments was lettuce; therefore, the data from the first season are not shown. Different letters above the bars indicate significant differences between seasons within a treatment according to Duncan's multiple range test $(P<0.05)$. The number of sclerotia per $100 \mathrm{~cm}^{3}$ of soil was not significantly $(P<0.05)$ different between treatments in 1996 spring; LLL-N (crop sequence: lettuce-lettuce-lettuce with residues removed) was significantly different from all other treatments in fall 1996; LLL-N was significantly different from all other treatments and so was LFL in spring 1997; and LLL-N was significantly different from LFL in fall 1997. Viability of sclerotia was not significantly different between treatments within a season during this study. 
Disease incidence in BBLL and BLBL treatments did not differ significantly in the last two seasons, indicating no effect of the broccoli cropping sequence, and that the reductions in disease incidence brought about by broccoli crops lasted at least three cropping seasons after it was discontinued.

Sclerotia population. At the Spence site, the numbers of sclerotia remained low for the entire five-season experiment, but differed significantly between seasons and between treatments in some seasons (Table 3; Fig. 2). In fall 1996, the population density of sclerotia in LLL-N and LLL-R were the highest among the treatments. In fall 1997, the numbers of sclerotia among treatments were not significantly different (Fig. 2).

At the Hartnell site, the population density of sclerotia in soil was not different between treatments at the time of thinning in spring 1996, reflecting the uniformity of sclerotial distribution before the start of the experiment (Fig. 3). The numbers of sclerotia in soil at thinning in succeeding crop cycles, however, were significantly different between treatments and seasons (Table $3)$. There was also a significant treatmentseason interaction (Table 3). With the exception of the last season, populations of sclerotia in LLLL increased significantly with each lettuce crop cycle throughout the study (Fig. 3). The numbers of sclerotia also increased after a lettuce crop in the fallow treatment (FLFL; Fig. 3). However, populations of sclerotia in BLBL and BBLL did not increase significantly until the last season, when lettuce followed lettuce (Fig. 4). The populations of sclerotia were low in BBLL after two crops of broccoli followed by a crop of lettuce, but increased after the second crop of lettuce. In BLBL, numbers of sclerotia tended to increase after a lettuce crop and decline after a broccoli crop, but most of these differences were not significant (Fig. 3). The numbers of sclerotia in all treatments when lettuce followed lettuce, however, were not significantly different at the end of the experiment.

Sclerotial density in soil samples collected at the end of two lettuce seasons were significantly higher than at the beginning of 1996 fall season. This increase was 57 and $70 \%$ in LLLL and FLFL, respectively (Fig. 4). However, this difference did not occur in spring 1997. The numbers of sclerotia in the soil remained the same from the beginning to the end of the season in treatments BBLL and BLBL when broccoli was grown, indicating that populations of sclerotia did not decline significantly during the growing season.

Viability of sclerotia. Viability of sclerotia recovered from soil generally ranged between 60 and $80 \%$ and did not vary significantly with cropping sequence at any
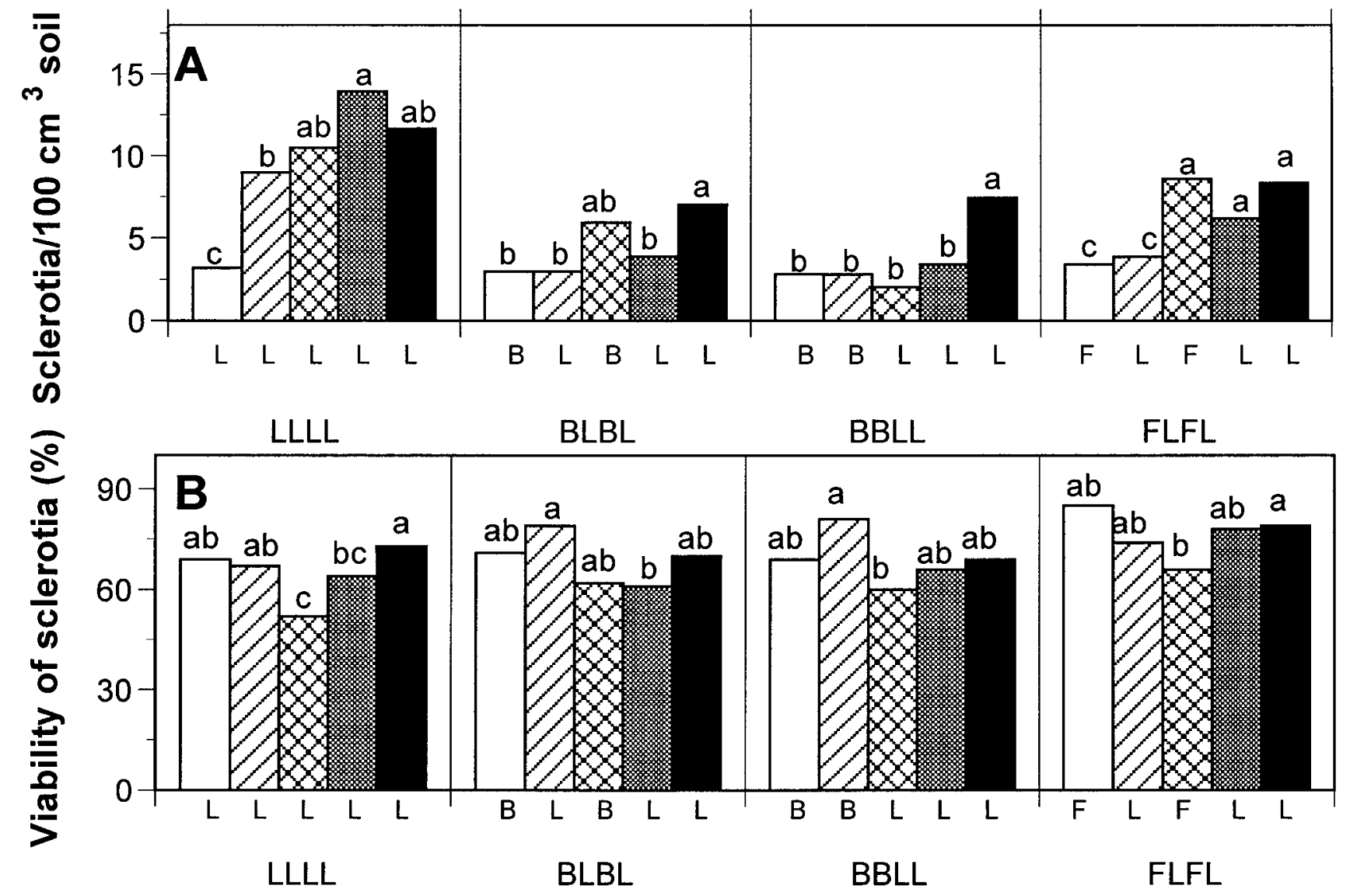

\section{Treatment}

\section{Spring 1996 \\ Fall 1996 \\ B8 Spring 1997 \\ Fall 1997 \\ Spring 1998}

Fig. 3. Effect of lettuce rotation with broccoli or fallow on the number of Sclerotinia minor sclerotia in $100 \mathrm{~cm}^{3}$ of soil and viability of sclerotia at the time of thinning lettuce at the Hartnell site. A, Numbers of sclerotia in $100 \mathrm{~cm}^{3}$ of soil and $\mathbf{B}$, viability of sclerotia in the different rotation treatments during 1996 to 1998 . Viability was calculated as the ratio of germinated sclerotia to the number recovered from soil. Letters $(\mathrm{L}=\mathrm{lettuce}, \mathrm{B}=$ broccoli, and $\mathrm{F}=$ fallow) below the bars indicate the crops planted or left fallow during that season. Different letters above the bars indicate significant differences between seasons within a treatment according to Duncan's multiple range test $(P<0.05)$. Treatment pairs that were significantly different for sclerotia per $100 \mathrm{~cm}^{3}$ of soil were: LLLL versus other treatments in fall 1996; LLLL and FLFL versus BBLL and BLBL in spring 1997; LLLL versus FLFL, BBLL, and BLBL; FLFL versus BBLL and BLBL in fall 1997; and LLLL versus BBLL, BLBL, and FLFL in spring 1998. Similarly, treatment pairs that were significantly different for viability of sclerotia were LLLL versus BLBL in fall 1997. 
one sampling time. The only possible exception is the relatively low viability of sclerotia recovered at the end of the 1996 fall lettuce season in the FLFL treatment at Hartnell (Fig. 4). Viability varied significantly with time or season (Table 4), but did so in a similar way in most rotation sequences (Figs. 2, 3, and 4).

\section{DISCUSSION}

Continuous lettuce cropping increased the incidence of lettuce drop caused by $S$. minor relative to the disease incidence resulting from lettuce cropping interrupted by broccoli or fallow periods. The benefits of rotations with broccoli, however, were more evident at a site with high inoculum density than at the site with low inoculum density. Furthermore, at the high inoculum
Table 4. Analysis of variance for effects of sequence of crop rotation (lettuce with broccoli or lettuce with fallow period) and season on sclerotial viability of sclerotia of Sclerotinia minor recovered from soil in two field sites during 1995 (Hartnell) or 1996 (Spence) to 1998

\begin{tabular}{lcccc}
\hline Field site, source & $\boldsymbol{d}_{\mathbf{n}} \mathbf{~ b}^{\mathbf{b}}$ & $\boldsymbol{d} \boldsymbol{f}_{\mathbf{d}}^{\mathbf{c}}$ & $\boldsymbol{F}^{\mathbf{d}}$ & $\boldsymbol{P r}>\boldsymbol{F}^{\mathbf{e}}$ \\
\hline Hartnell & & & & \\
Season & 3 & 32 & 8.77 & 0.0002 \\
Treatment & 3 & 32 & 1.61 & 0.2054 \\
Season-treatment & 9 & 32 & 1.18 & 0.3423 \\
Spence & & & & \\
Season & 3 & 71 & 18.07 & 0.0001 \\
Treatment & 4 & 71 & 1.05 & 0.3886 \\
Season-treatment & 12 & 1.67 & 0.0930 \\
\hline
\end{tabular}

${ }^{a}$ Soil samples were taken at the time lettuce was thinned in each crop cycle.

${ }^{b}$ Numerator degrees of freedom.

${ }^{c}$ Denominator degrees of freedom.

d Variance ratio.

${ }^{\text {e }}$ Probabilities associated with individual $F$ tests.
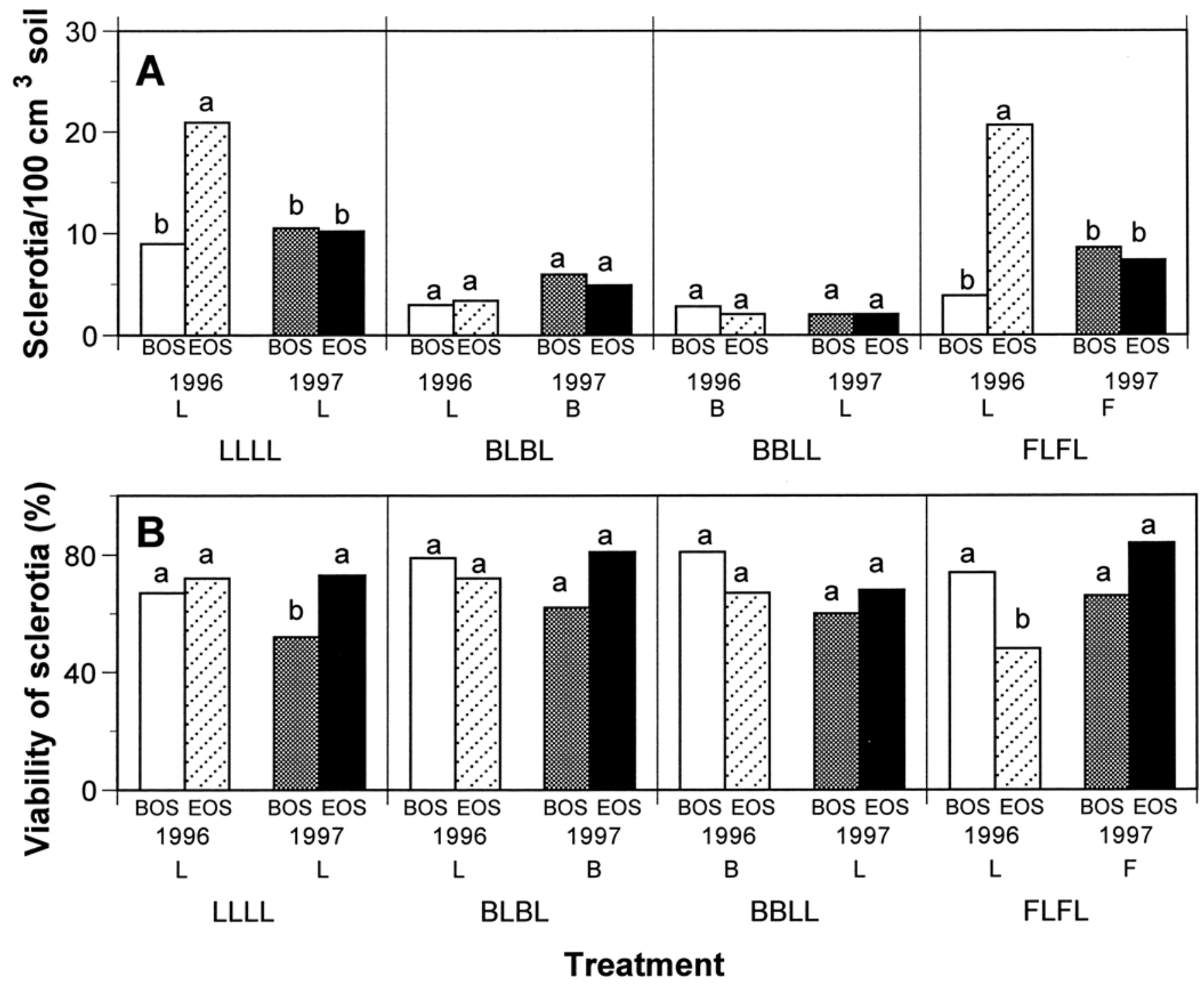

Fig. 4. Effect of lettuce rotation with broccoli or fallow on the number of Sclerotinia minor sclerotia in $100 \mathrm{~cm}^{3}$ of soil and viability at the time of thinning or at harvest at Hartnell. A, Numbers of sclerotia in $100 \mathrm{~cm}^{3}$ of soil and $\mathbf{B}$, viability of sclerotia through the seasons with different rotation treatments in 1996-97. Viability was calculated as the ratio of germinated sclerotia to the number recovered from soil. Different letters above the bars indicate significant differences between seasons within a treatment according to Duncan's multiple range test $(P<0.05)$. $\mathrm{L}=$ lettuce, $\mathrm{B}=$ broccoli, and $\mathrm{F}=$ fallow. Numbers of sclerotia per $100 \mathrm{~cm}^{3}$ of soil in BBLL and BLBL at the beginning of the season (BOS) and end of season (EOS) were significantly lower than in FLFL and LLLL in fall 1996 and spring 1997 but not during spring 1997, when FLFL and BLBL resulted in statistically nonsignificant numbers of sclerotia. Significant differences between treatments for viability of sclerotia were observed only during fall 1996 in the end of season samples, when viability in the two broccoli treatments was significantly lower than in other treatments. 
density site, rotation with broccoli reduced soilborne $S$. minor sclerotia and disease significantly more than the fallow period when the effects of treatments were assessed on the final lettuce crop.

Crop rotations generally have been unsuccessful for managing pathogens such as $S$. minor because of the wide host range of the pathogen, persistence of sclerotia in soil for extended periods, and lack of candidate crops that can be used in a rotation. However, in greenhouse as well as field studies, S. minor failed to infect 5-weekold broccoli plants, making it a potentially suitable candidate for rotations with lettuce (B. M. Wu and K. V. Subbarao, unpublished). In greenhouse experiments, broccoli residue incorporation into infested soil also reduced numbers of viable $S$. minor sclerotia (K. V. Subbarao, unpublished data). Based on these preliminary results, we examined the efficacy of lettuce rotations with broccoli for the management of lettuce drop in coastal California. Results suggest that crop rotation with broccoli is an effective method of managing lettuce drop, particularly in fields with higher inoculum levels. Another factor that makes broccoli an attractive crop for lettuce drop management is its extensive production in coastal California. Thus, by slightly modifying their cropping systems, growers can exploit the disease-suppressive benefits of broccoli. Alternatively, applying broccoli residues collected from food-processing facilities may provide similar results $(25,26,30)$.

In the high inoculum density soil, rotations with broccoli or fallow greatly reduced the population of sclerotia compared with continuous lettuce cropping. Each crop in the continuous lettuce cropping systems presumably contributes a greater number of infected lettuce plants from which sclerotia are continually added to the soil each season relative to other cropping systems. Another factor that influences this augmentation of soilborne sclerotia is the conversion of infected lettuce biomass, including the taproot systems, into pathogen biomass over an extended period. In contrast, sclerotial density did not increase during a broccoli crop, supporting the theory that it is not a host to $S$. minor. Furthermore, the numbers of sclerotia decreased after residue incorporation in broccoli plots, suggesting that the broccoli residue had a deleterious effect on sclerotial population. In the high inoculum density soil, reductions in the population density of sclerotia and disease incidence between BBLL and BLBL treatments were similar, suggesting that the number of broccoli crops rather than the sequence of lettuce rotations with broccoli was critical for reducing the numbers of $S$. minor sclerotia in soil.

Removal of the aboveground broccoli residue at the Spence site (low inoculum density) did not alter the effects of broccoli rotation on the population of sclerotia or subsequent disease reduction. Also, inoculum reductions at the Spence road site did not give corresponding reductions in disease incidence. In fact, at the Spence field where inoculum densities were lower, disease incidence actually decreased seasonally in all treatments during the five seasons of this study. Even though the numbers of sclerotia increased seasonally, the inoculum density was still below the threshold that leads to a high lettuce drop incidence (6). Although this contributed to the low lettuce drop incidence, it also partially explains why rotation effects were not significant at this site.

Regardless of the site, viability of the recovered sclerotia was not affected by rotation treatments but was affected by time and season. This was not totally unexpected because viability could only be tested on sclerotia recovered from soil (because degenerated sclerotia are not redeemed during wet sieving). The sclerotia affected adversely by broccoli residue or time in fallow soil may have decayed rapidly and, consequently, become nonretrievable.

Broccoli crop residues have been reported to have deleterious effects on $V$. dahliae $(25,26,30)$. The suppressive effects of broccoli residue on $V$. dahliae or the incidence of Verticillium wilt on cauliflower were not altered by either the irrigation method or irrigation regimes (29). However, the suppressive effects of broccoli on $V$. dahliae are greater when the soil temperature at the time of residue incorporation is at least $20^{\circ} \mathrm{C}$ (25). In this study, the broccoli residue incorporation coincided with the onset of summer during the first season and occurred in the summer during subsequent seasons. Thus, conditions for the suppressive activity of broccoli are likely to have been optimal during the course of this study and the observed results also were consistent with the results obtained on $V$. dahliae $(25,26,29)$. Other crucifer crops have similar effects on Fusarium oxysporum f. sp. conglutinans (21), Aphanomyces euteiches (19), and Didymella bryoniae (14). The use of crucifer crops for pathogen or disease suppression has largely relied on the knowledge that volatile chemicals released by the breakdown products of glucosinolate-containing residues are toxic to pathogens $(7,14,16)$. Our study deviates from these assumptions primarily because the choice of broccoli was made after a thorough testing of the pathogenicity of S. minor on broccoli revealed that it was not a host. Thus, the crop is unlikely to augment soil inoculum levels as demonstrated in this study. Like most other crucifers, broccoli also contains glucosinolates that break down into volatile chemicals that may be deleterious to plant pathogens. However, because of the volatile nature of these breakdown products, their retention time in soil is limited. Sclerotia are known to survive for up to 10 years in the soil environment (20); therefore, it is unlikely that transient exposure to the volatile chemicals would be responsible for the level of reductions in sclerotia observed in this study. It is possible, however, that those volatile products from the breakdown of broccoli residues could predispose $S$. minor sclerotia for attack by other soil microorganisms. More detailed studies to elucidate the mechanism of broccoli-mediated suppression of $S$. minor are required.

\section{ACKNOWLEDGMENTS}

We thank S. Benzen for field operations; J. Hubbard, M. Orozco, and M. Abarca for technical assistance; B. Mackey for suggestions on the statistical analyses; and the USDA Salinas and Hartnell College for use of their facilities.

\section{LITERATURE CITED}

1. Abawi, G. S., Robinson, R. W., Cobb, A. C., and Shail, J. W. 1980. Reaction of lettuce germ plasm to artificial inoculation with Sclerotinia minor under greenhouse conditions. Plant Dis. 64:668-671.

2. Adams, P. B. 1990. The potential of mycoparasites for biological control of plant diseases. Annu. Rev. Phytopathol. 28:59-72.

3. Adams, P. B., and Wong, J. A, L. 1991. The effect of chemical pesticides on the infection of sclerotia of Sclerotinia minor by the biocontrol agent Sporidesmium sclerotivorum. Phytopathology 81:1340-1343.

4. Alvarez, J., Datnoff, L. E., and Nagata, R. T. 1992. Crop rotation minimizes losses from corky root in Florida lettuce. HortScience 27:66-68.

5. Davies, J. M. L. 1991. Sclerotinia on peas: implications for yield and crop rotation. Asp. Appl. Biol. 27:351-354.

6. Dillard, H. R., and Grogan, R. G. 1985. Relationship between sclerotial spatial pattern and density of Sclerotinia minor and the incidence of lettuce drop. Phytopathology 75:90-94.

7. Gamliel, A., and Stapleton, J. J. 1993. Characterization of antifungal volatile compounds evolved from solarized soil amended with cabbage residues. Phytopathology 83:899905.

8. Hao, J. J. 2000. Comparative analyses of lettuce drop epidemics caused by Sclerotinia Minor and S. Sclerotiorum and disease management through crop rotation. Ph.D. thesis University of California, Davis

9. Hao, J. J., Subbarao, K. V., Hubbard, J. C., and Koike, S. T. 2000. Effects of broccoli rotation on lettuce drop caused by Sclerotinia minor and sclerotia in soil. (Abstr.) Phytopathology 90:S34.

10. Hubbard, J. C., Subbarao, K. V., and Koike, S T. 1997. Development and significance of dicarboximide resistance in Sclerotinia minor isolates from commercial lettuce fields in California. Plant Dis. 81:148-153.

11. Imolehin, E. D., and Grogan, R. G. 1980 Factors affecting survival of sclerotia, and effects of inoculum density, relative position, and distance of sclerotia from the host on infection of lettuce by Sclerotinia minor. Phytopathology 70:1162-1167.

12. Inman, J. W., Greathead, A. S., Lenker, D. and Agamalian, H. S. 1982. Improved plow design for soil borne disease control. Pages 140-149 in: Annu. Iceberg Lettuce Res. Rep. Crop Year 1981. CILRAB, Salinas, CA.

13. Keinath, A. P. 1996. Soil amendment with cabbage residue and crop rotation to reduce gummy stem blight and increase growth and yield of watermelon. Plant Dis. 80:564-570. 
14. Lewis, J. A., and Papavizas, G. C. 1971. Effect of sulfur-containing volatile compounds and vapors from cabbage decomposition on Aphanomyces euteiches. Phytopathology 61:208-214.

15. Marcum, D. B., Grogan, R. G., and Greathead, A. S. 1977. Fungicide control of lettuce drop caused by Sclerotinia sclerotiorum 'minor'. Plant Dis. 61:555-559.

16. Mayton, H. S., Olivier, C., Vaughn, S. F., and Loria, R. 1996. Correlation of fungicidal activity of Brassica species with allyl isothiocyanate production in macerated leaf tissue. Phytopathology 86:267-271.

17. Melzer, M. S., and Boland, G. J. 1994. Epidemiology of lettuce drop caused by Sclerotinia minor. Plant Pathol. 16:170-176.

18. Mol, L., Scholte, K., and Vos, J. 1995. Effects of crop rotation and removal of crop debris on the soil population of two isolates of Verticillium dahliae. Plant Pathol. 44:1070-1074.

19. Muehlchen, A. M., Rand, R. E., and Parke, J. L. 1990. Evaluation of crucifer green manures for controlling Aphanomyces root rot of peas.
Plant Dis. 74:651-656.

20. Purdy, L. H. 1979. Sclerotinia sclerotiorum: History, diseases and symptomatology, host range, geographic distribution, and impact. Phytopathology 69:875-880.

21. Ramirez-Villapudua, J., and Munnecke, D. E. 1988. Effect of solar heating and soil amendments of cruciferous residues on Fusarium oxysporum f. sp. conglutinans and other organisms. Phytopathology 78:289-295.

22. Steadman, J. R. 1979. Control of plant diseases caused by Sclerotinia species. Phytopathology 69:904-907.

23. Subbarao, K. V. 1998. Progress toward integrated management of lettuce drop. Plant Dis. 82:1068-1078

4. Subbarao, K. V., Dacuyan, S., Koike, S. T., and Jackson, L. E. 1994. Evaluation of three quantitative assays for Sclerotinia minor. Phytopathology 84:1471-1475.

25. Subbarao, K. V., and Hubbard, J. C. 1996. Interactive effects of broccoli residue and temperature on Verticillium dahliae microsclerotia in soil and on wilt in cauliflower.
Phytopathology 86:1303-1310.

26. Subbarao, K. V., Hubbard, J. C., and Koike, S. T. 1999. Evaluation of broccoli residue incorporation into field soil for Verticillium wilt control in cauliflower. Plant Dis. 83:124-129.

27. Subbarao, K. V., Hubbard, J. C., and Schulbach, K. F. 1997. Comparison of lettuce diseases and yield under subsurface drip and furrow irrigation. Phytopathology 87:877883.

28. Subbarao, K. V., Koike, S. T., and Hubbard, J. C. 1996. Effects of deep plowing on the distribution and density of Sclerotinia minor sclerotia and lettuce drop incidence. Plant Dis. 80:28-33.

29. Walker, A. 1987. Further observations on the enhanced degradation of iprodione and vinclozolin in soil. Pestic. Sci. 21:219-231.

30. Xiao, C. L., Subbarao, K. V., Schulbach, K. F., and Koike, S. T. 1998. Effects of crop rotation and irrigation on Verticillium dahliae microsclerotia in soil and wilt in cauliflower. Phytopathology 88:1046-1055. 